\title{
The Rate of Benzo[a]pyrene Apparent Loss in a Natural and Manure Amended Clay Loam Soil
}

\author{
MERVIN P. COOVER and RONALD C. SIMS \\ Utah Water Research Laboratory and \\ Department of Civil and Environmental Engineering \\ Utah State University \\ Logan, UT 84322-8200
}

\begin{abstract}
A study was conducted to evaluate the rate of Benzo[a]pyrene apparent loss from a previously uncontaminated agricultural clay loam soil and to determine the effect of cow manure, as organic substrate amendment, on $B[a] P$ apparent loss. Soil microcosms were spiked with $10 \mu \mathrm{g} / \mathrm{g} \mathrm{B}[\mathrm{a}] \mathrm{P}$ and incubated at $20^{\circ} \mathrm{C}$. Triplicate sets of microcosms were periodically removed from incubation and solvent extracted. Concentrations of $\mathrm{B}[\mathrm{a}] \mathrm{P}$ in the soil were determined by HPLC analysis of the extracts. Under the conditions of this study manure was an ineffective amendment for increasing the rate of $B[a] P$ apparent loss in the Durant clay loam soil. In addition there was no observable increase in apparent loss of $B[a] P$ during a second $B[a] P$ application period. A first order kinetic model was found to adequately characterize the loss of $B[a] P$ in this study but tended to overestimate degradation during an extended incubation period.
\end{abstract}

\section{INTRODUCTION}

To properly dispose of hazardous organic wastes by land treatment, an understanding of the rates of waste constituent degradation, transformation and immobilization in the soil system is essential. U.S. Environmental Protection Agency (EPA) regulations stipulate that methods be developed for enhancing treatment, and it is with knowledge of degradation rates that potential soil management options are, in part, evaluated [1]. Because biodegradation by soil microorganisms is considered the primary treatment mechanism for nonvolatile organic wastes $[2,3,4]$, management approaches for improving treatment rate are directed towards sustaining a high level of microbial activity. Possible options for improving treatment rate include augmenting the soil nutrient reservoir, maintaining optimal soil moisture levels, and increasing the level of microbial activity with organic substrate additions.

The land treatment of wastes containing polycyclic aromatic hydrocarbons (PAHs) has recently received attention because many PAHs are carcinogenic and are commonly found in petroleum industry wastes which are currently land treated $[3,5,6]$. Within the PAH class of compounds $B[a] P$ has been studied extensively because of its carcinogenicity and ubiquity in the environment [7,8]. Reported 
here are results of a study that was conducted to evaluate the rate of Benzo[a]pyrene (B[a]P) apparent loss from a previously uncontaminated agricultural clay loam soil and to determine the effect of cow manure, as an organic substrate amendment, on B[a]P apparent loss. Apparent loss refers to the observed decline in concentration of the parent compound without determination of the specific treatment mechanisms involved.

Both procaryotic and eucaryotic organisms common to soils are capable of oxidizing $B[a] P$ in the presense of a growth substrate under laboratory conditions $[9,10]$, but no organisms capable of growth on $B[a] P$ alone have been isolated [8]. The potential, therefore, exists for optimizing conditions in soils to promote the microbiologically mediated degradation of B[a]P. Khesina et al. [11] found substantial degradation of B[a]P in soil with a history of oil contamination but reduced degradation in an uncontaminated control soil. Sims and Overcash [12] demonstrated that analog enrichment with phenanthrene sigificantly reduced the half life of $B[a] P$ in a soil. These findings indicate that degradation of $B[a] P$ and other recalcitrant PAHs may be stimulated during land treatment of complex wastes which contain potential analog substrates in the form of readily degradable PAHs. During the closure period of a facility managed for the treatment of PAH containing wastes, methods for sustaining continued degradation of hazardous constituents to background levels are of interest and such methods necessarily must not include the addition of more hazardous materials. Manure is an inexpensive and safe material that may be of value as an organic substrate amendment which can sustain a high level of microbial activity and serve as a microbial inoculum. Sims [4] found that a manure amendment and $\mathrm{pH}$ adjustment increased the apparent loss of severaI PAH including $B[a] P$ during incubation of a complex fossil fuel waste in soil.

MATERIALS AND METHODS

\section{Approach}

Soil microcosms were prepared in glass beakers, spiked with a standard solution of $\mathrm{B}[\mathrm{a}] \mathrm{P}$ to a concentration of $10 \mu \mathrm{g} / \mathrm{g}$, and placed in an incubation chamber at $20+/-2^{\circ} \mathrm{C}$. To prevent low soil moisture from adversely affecting microbial populations the moisture content of the microcosm soils was maintained between 60 and $75 \%$ of the soil water retention at $-1 / 3$ barr matric potential through regular additions of deionized water. Periodically, triplicate sets of microcosms were removed from incubation and solvent extracted using methylene chloride. Concentrations of $\mathrm{B}[\mathrm{a}] \mathrm{P}$ in the soil were determined by high performance liquid chromatography (HPLC) analysis of the extracts.

\section{Standards and Reagents}

The B[a]P used for application to soil microcosms was 998 pure and was obtained from Foxboro Co. (New Haven, CT). Standard solutions for spiking soil microcosms with B[a]P were prepared in HPLC grade dichloromethane. Analytical $B[a] P$ standards for HPLC analysis were prepared in HPLC grade acetonitrile using analytical standards obtained from Foxboro Co.

\section{Breparation of Soil Microcosms}

A bulk sample of clay loam (Durant) was obtained from a U.S. EPA Field Test Facility in Ada, Oklahoma. The soil was air dried and screened to <2 $\mathrm{mm}$ prior to use. Soil properties determined prior to initiation of the study include a soil $\mathrm{pH}$ of $6.6,2.9 \%$ by weight organic carbon, $0.03 \%$ by weight total phosphorus, $0.21 \%$ by weight total nitrogen, and a moisture content of $42 \%$ by weight of the soil water retention at $-1 / 3$ barr matric potential. Cow manure was obtained wet 
and was also air dried and screened to $<2 \mathrm{~mm}$. Microcosms consisted of $20 \mathrm{~g}$ of soil in $250 \mathrm{~mL}$ glass beakers and a glass rod for mixing added materials with the soil. Amended soils also contained 2 o by wt. manure (dry wt. basis). Each beaker was capped with polyethylene film (Glad Wrap; Dow Chemical Co.) to reduce moisture loss during incubation. Initial soil respiration rates (data not shown) indicated that the high oxygen permeability of the polyethylene film and periodic removal of microcosm covers to replenish soil moisture would ensure that oxygen levels in the soil remained high during incubation.

To initiate incubation the moisture content of each microcosm was adjusted to $30.5 \%$ with deionized water. The microcosms were capped with polyethylene film and placed in an incubation chamber at $20+/-2^{\circ} \mathrm{C}$. After a 10 day preincubation period, $1 \mathrm{~mL}$ of the standard $B[a] P$ spiking solution was added to each microcosm and thoroughly mixed with the soil using a glass stirring rod. Initial concentration of $\mathrm{B}[\mathrm{a}] \mathrm{P}$ in the soil was $10 \mu \mathrm{g} / \mathrm{g}$. The microcosms were left open to the atmosphere at $20+/-2^{\circ} \mathrm{C}$ to permit the carrier solvent to evaporate before remoistening the soil and capping the beakers. During incubation, deionized water was periodically added to each microcosm to compensate for evaporative losses. The moisture content of the soils was maintained between 60 and $75 \%$ of water holding capacity.

After 160 days of incubation a subset of manure amended and unamended soil microcosms was respiked with $10 \mu \mathrm{g} / \mathrm{g}$ of $\mathrm{B}[\mathrm{a}] \mathrm{P}$ following the same procedure described previously. No additional manure was added to this subset of microcosms.

\section{Extraction and Analysis}

Soil microcosms at each temperature were periodically sampled in triplicate and prepared for extraction by removing the polyethylene covers and permitting the soil to air dry for 18-24 hours. The Tissumizer (Tekmar; Cincinnati, OH) homogenization system used for the soil extractions consisted of the Model SDT-1810 motor, Model SDT-182EN shaft and generator assembly, and Model TR-10 speed controller. The $20 \mathrm{~g}$ of soil in each microcosm was homogenized for 45 seconds in the original microcosm beaker with $140 \mathrm{~mL}$ of HPLC grade dichloromethane. After permitting the solids to settle in the beaker, the supernatant was transferred to a Gelman stainless steel pressure filter fitted with a whatman GF/D glass fiber filter. The solids were reslurried with $40 \mathrm{ml}$ of solvent and transferred with rinsing to the pressure filter. Extract solution was pressure filtered into a $600 \mathrm{~mL}$ glass beaker and transferred to a drying column containing $40 \mathrm{~g}$ of anhydrous $\mathrm{Na}_{2} \mathrm{SO}_{4}$. The dried extract was concentrated in a Kuderna-Danish apparatus to a volume of approximately $0.5 \mathrm{~mL}$ and was brought to a final volume of 5 or $10 \mathrm{~mL}$ with HPLC grade acetonitrile for HPLC analysis.

The extracts were analyzed by reversed-phase HPLC using a Shimadzu Model LC-6A liquid chromatograph equipped with Model SCL-6A system controller, Model SIL-6A autosampler, Model C-R3A computing integrator and Model SPD-6A variable wavelength UV detector. Chromatography was performed on a $4 \mathrm{~mm} \times 15 \mathrm{~cm}$ ODS column with $5 \mathrm{u}$ packing (Supelco; LC-PAH). The mobile phase composition was $80 \%$ acetonitrile in water and the flow rate was $2 \mathrm{~mL} / \mathrm{min}$.

\section{RESULTS AND DISCUSSION}

All soil microcosms were prepared and spiked with B[a]P on the same day, and the first set of extractions $(t=0$ d) was conducted within 24 hours. Initial recovery of $B[a] P$ from the soil was between $60 \%$ and $70 \%$ of the amount of compound initially added.

The loss of B[a]P over two application periods in both unamended and manure amended soil is presented in Figure 1. During each application period a gradual reduction in the concentration of $B[a] P$ was observed in both soils. During the 
first application period the trend was markedly concave upward whereas during the second application period the trend was more linear. Consistently higher $B$ [a]P extraction recoveries were obtained from the manure amended soil.

The data in Figure 1 were analyzed using a first order kinetic model, and the results are presented in Figure 2. Compound half lives based on the first order rate coefficients in Figure 2 ranged from 100 to 175 days which is in the range of 30 to 420 days reported by Sims and overcash [8] and slightly less than the half lives of 218 and 347 days reported by PACE [16] for the degradation of $B[a] P$ in soils. Rate coefficients for $B[a] P$ loss in amended and unamended soil were compared for each application period. With 95\% confidence there was no significant difference between coefficients indicating that, despite the differences in extraction recoveries between amended and unamended soil, manure had no observable effect on the rate of $B[a] P$ degradation. Other studies have demonstrated that readily utilizable carbon and energy sources fail to stimulate microbial degradation of PAHs and other aromatic compounds $[3,13,14]$. Therefore the addition of readily utilized and inexpensive organic materials, such as manure, to land treatment soils may often be ineffective in stimulating degradation of recalcitrant organic compounds.

In comparing rate coefficients between application periods it was determined that with $95 \%$ confidence the rate of $B[a] P$ loss in unamended soil was slightly greater during the first period. There was no difference, however, between the two rate coefficients for loss of $B[a] P$ in amended soil. Thus the changes in soil physical, chemical, and microbiological properties which occured during the first 160 days of incubation had little effect on the observed apparent loss of $B[a] P$.

Results of the study to evaluate the long term degradation of $B[a] P$ during a single substrate application period in manure amended soil are shown in Figure 3. The applicability of a first order model in representing the observed decline in soil $B$ [a]P concentrations can be addressed with reference to Figure 4. Analysis of the least squares residuals indicated that predicted values of $B[a] P$ concentration from the equation of the regression line were systematically underestimated during the first three to four weeks of incubation, overestimated between day 50 and 150, and again underestimated towards the end of the incubation period. PACE (16) noted similar trends for the degradation of phenanthrene, anthracene, and fluoranthene in an agricultural sandy loam soil [16]. They characterized the degradation kinetics by dividing the observed trends into two phases for modeling. A first order model for describing the degradation curves in Figures 1 and 3 was a good approximation to the observed trends. Caution must be exercized, however, when using data from short term incubation studies as overestimation of the long term rates of degradation may result. Furthermore use of any model to characterize degradation kinetics must be justified on a case-by-case basis as soil/waste properties are likely to affect the form of the degradation curve.

\section{CONCLUSIONS}

Under the conditions of this study manure was an ineffective amendment for increasing the rate of $B[a] P$ apparent loss in the unacclimated Durant clay loam soil. This observation coupled with results from other studies indicate that organic amendments which are readily utilized for carbon and energy are often ineffective in stimulating degradation of recalcitrant organic compounds. A first order kinetic model was found to adequately characterize the loss of Bla]P in this study but may tend to overestimate degradation over long incubation periods. 


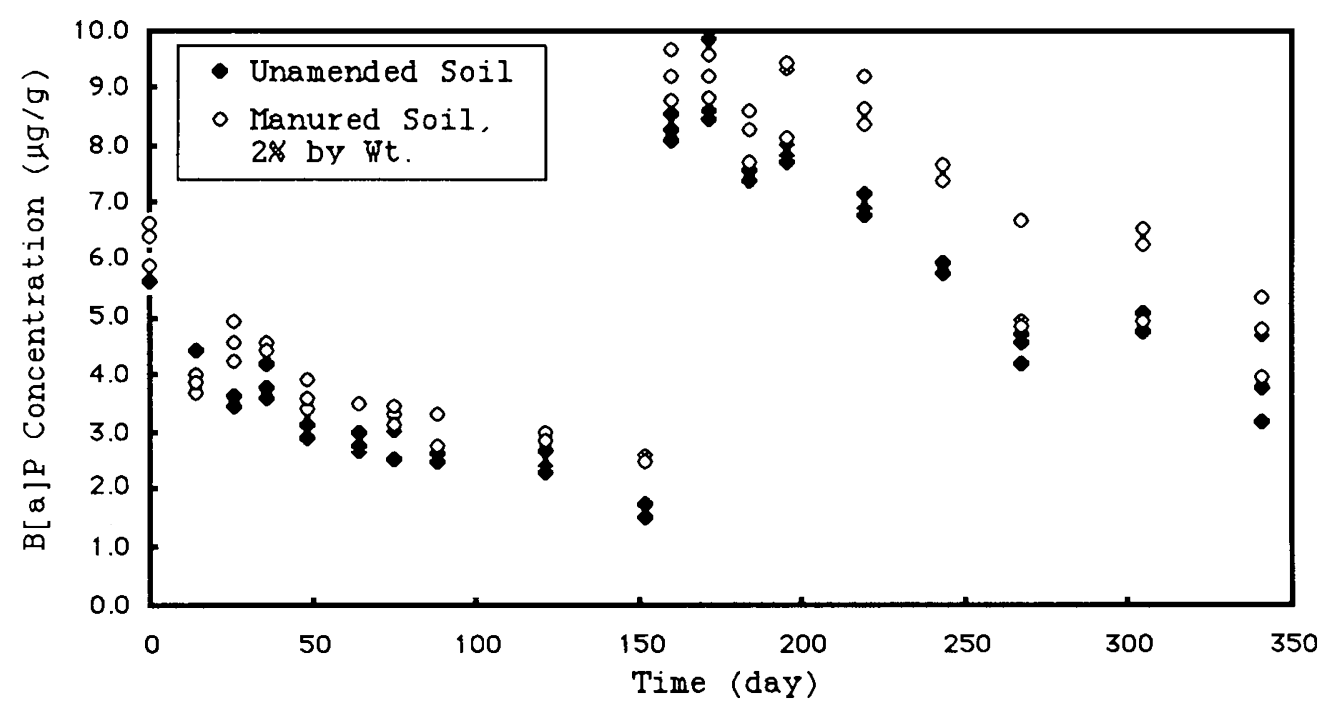

Figure 1. Apparent Loss of B[a]P Over the Course of Two Application Period in Manure Amended and Unamended Durant Clay Loam.

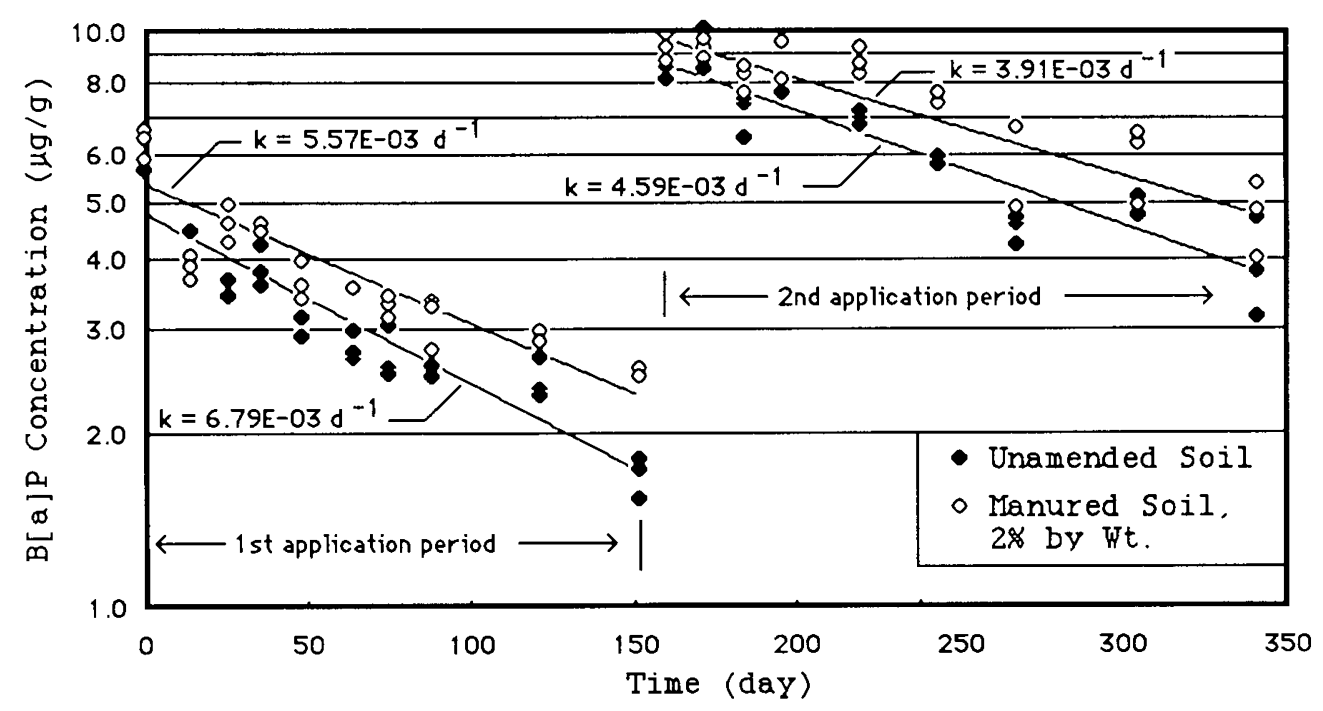

Figure 2. Analysis of Trends in Figure 1 Using a First Order Kinetic Model. 


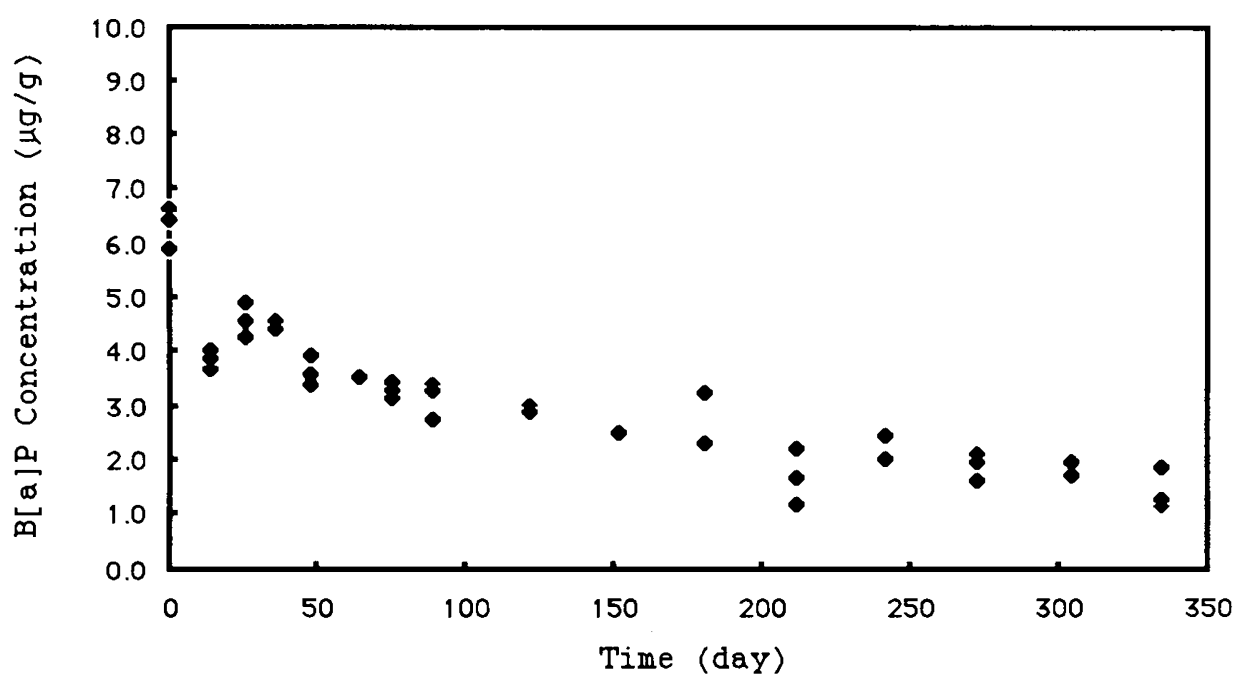

Figure 3. Extended $B[a] P$ Degradation Study Results in Manure Amended Soil at $20^{\circ} \mathrm{C}$. The Initial Concentration of $\mathrm{B}[\mathrm{a}] \mathrm{P}$ Was $10 \mathrm{\mu g} / \mathrm{g}$.

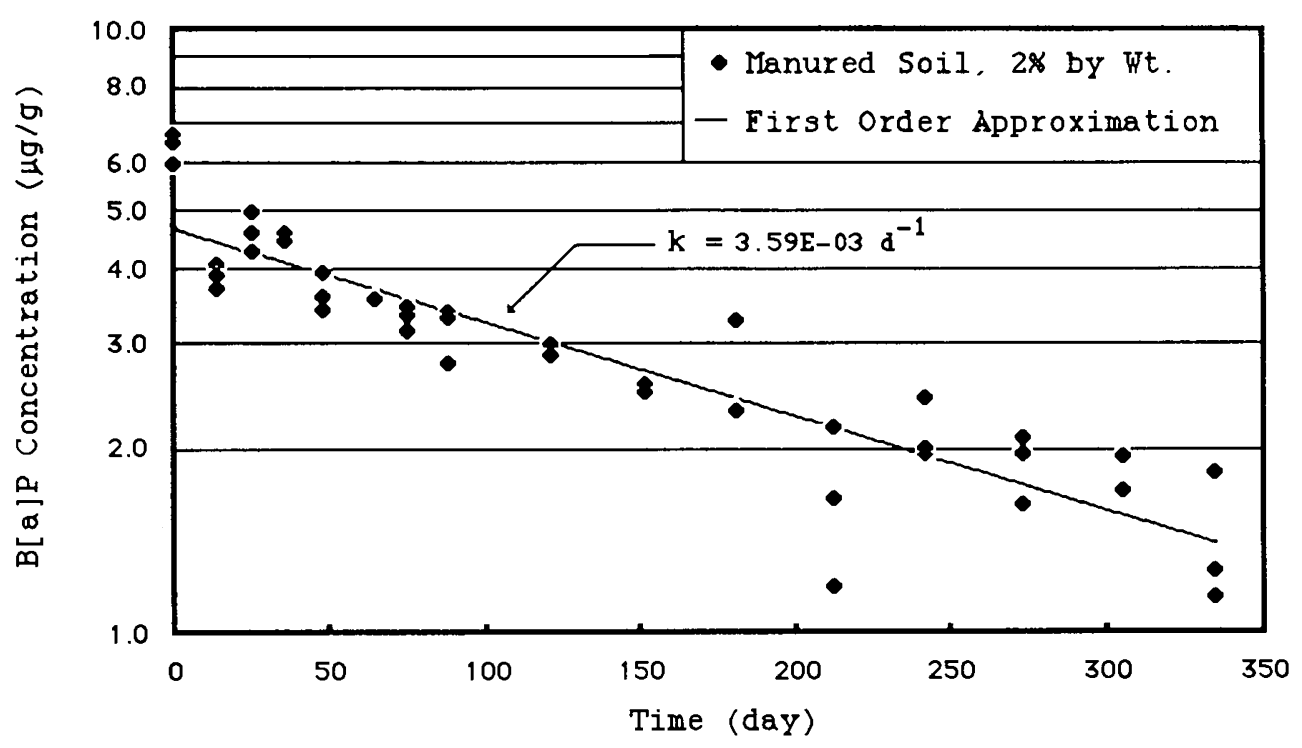

Figure 4. First Order Plot of Data From the Extended B[a]P Degradation Study in Manure Amended Soil. 
This work was sponsored by the U.S. Environmental Protection Agency, Robert S. Kerr Environmental Research laboratory, Ada, OK, under cooperative agreement number CR-813211. John E. Matthews was the project officer. This work has not been subjected to the Agency's peer review and therefore does not necessarily reflect the views of the Agency, and no official endorsement should be inferred.

\section{REFERENCES}

1. "Permit Guidance Manual on Hazardous waste Land Treatment Demonstrations", Final Draft, Office of Solid Waste, U.S. Environmental Protection Agency, EPA 530/SW86-032, 1986.

2. Loehr, D.C., Land Treatment: A waste Management Alternative, Loehr, R.C. and Malina, J.F., Eds., University of Texas Center for Research in Water Resources, Austin, 1986, 7 .

3. Bossert, I., Kachel, W.M., and Bartha, R., Appl. and Environ. Microbiol., 47, 763 (1984).

4. Sims, R.C., Land Treatment: A waste Management Alternative, Loehr, R.C. and Malina, J.F., Eds., University of Texas Center for Research in Water Resources, Austin, 1986, 151.

5. Ryan, J., Land Treatment: A waste Management Alternative, Loehr, R.C. and Malina, J.F., (Eds.), University of Texas Center for Research in Water Resources, Austin, 1986, 347.

6. U.S.EPA., Soil-Waste Treatability Studies, Vol 1, waste Characterization and Loading Rate Determination, and Vol 2, Degradation, Transformation, and Immobilization of Waste Constituents, Robert S. Kerr Environmental Research Laboratory, U. S. Environmental Protection Agency. Cooperative Agreement No. CR-810979, 1986 .

7. Edwards, N.T., J. Environ. Qual., 12, 427, (1983).

8. Sims, R.C., and Overcash, M.R., Residue Reviews, 88, 1 (1983).

9. Cerniglia, C.E., Reviews in Biochemical Toxicology. Vol 3, E. Hodgson, J.R. Bend, and R.M. Philpot (Eds.) Elsevier North Holland, Inc., New York, 1981, p. 321-361.

10. McKenna, E.J., Biodegradation of polynuclear aromatic hydrocarbon pollutants by soil and water microorganisms. Presented at the 70 th annual meeting of the American Institute of Chemical Engineers, Nov. 13-17, New York, (1977).

11. Khesina, A. Ya, Shcherback, N.P., Shabad, L.M., and Vostrov, I.S., Byulleten Eksperimental'noi Biologii i Meditsiny, 68, 70, (1969).

12. Sims, R.C., and Overcash, M.R., Symposium Proceedings, Ervironmental Aspects of Fuel Conversion Technology - VI, A Symposium on Coal-Based synfuels, EPA-600/9-82-017, 1986, p. 218-230.

13. Graveel, J.G., Sommers, L.E., and Nelson, D.W., J. Environ. Qual., 15, 53, (1986)

14. Bauer, J.E., and Capone, D.G., Appl. and Environ. Microbiol., 50, 81, (1985). 
15. Brunner, W., Sutherland, F.H., and Focht, D.D., J. Environ. Qual., 14, 324, (1985).

16. "The Persistence of Polynuclear Aromatic Hydrocarbons in Soil", Petroleum Association for Conservation of the Canadian Environment, Ottawa, Ontario, Report No. 85-2, 1985.

Ronald C. Sims Utah Water Research Laboratory Utah State University Logan, UT 84322-8200 